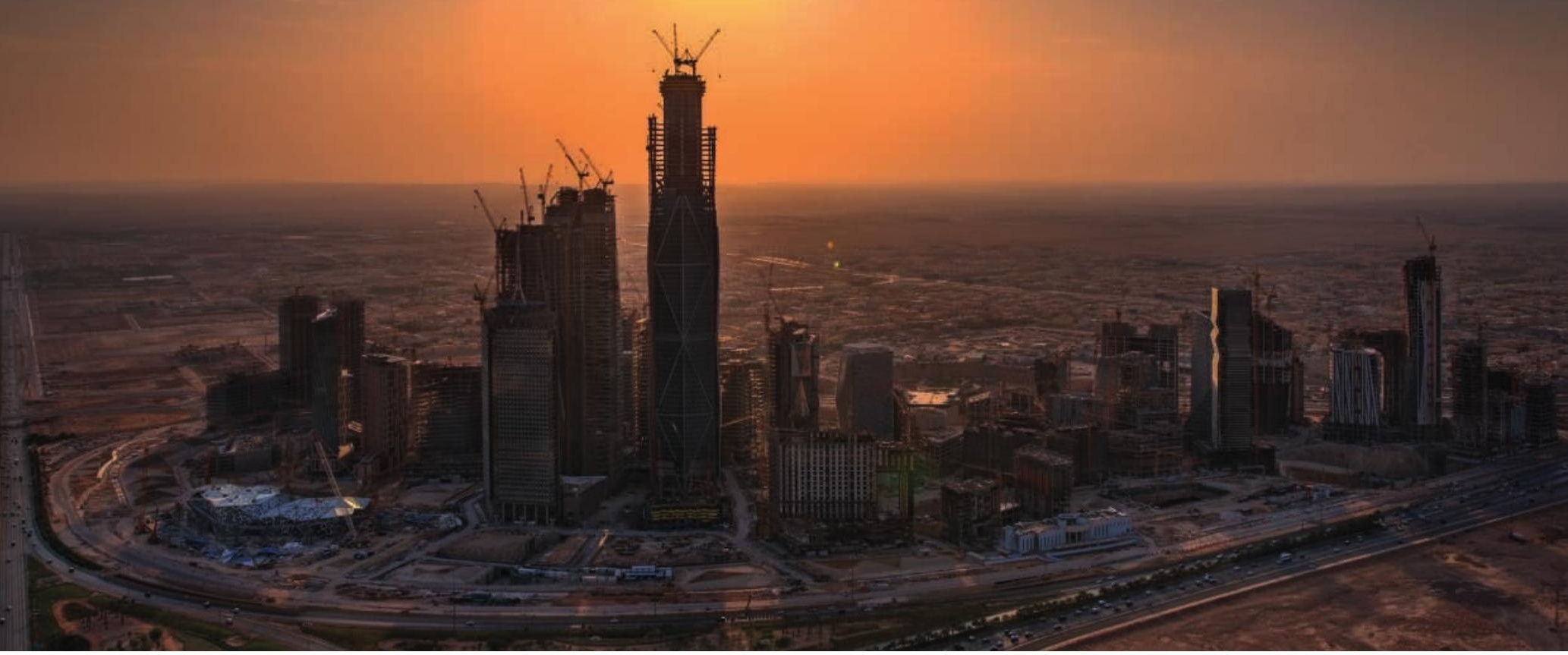

The King Abdullah financial district in Riyadh is a new development in line with the kingdom's plans to change its economic structure.

\section{DRILLING FOR EXCELLENCE}

$\mathrm{B}$ y a considerable margin, Saudi Arabia is the scientific leader of the Arab world. It ranks just outside the world's top 30 nations for its contribution to high-quality research published in journals monitored by the Nature Index, 19 places higher than the closest Arab states - though even that belies the true scale of the lead it holds (see page S62).

This has not always been the case. An upsurge in funding for research and development came as recently as 2010, and the quantity of research produced within the country has followed a similarly steep trajectory. But the oil money that has supported this rise over the last decade can no longer be relied upon. The price per barrel has tumbled since 2014, leaving Saudi Arabia with a budget deficit of nearly US\$100 billion in 2015.

The Saudi government is looking to its academic sector to supplement the economy and reduce reliance on oil. Universities are being encouraged to exploit commercial value in their research, with specific targets around patenting and start-up companies laid out in the country's science strategy. They do not, however, operate in a vacuum: the culture outside these institutions' walls must also change if the policy is to be successful (page S75).
Saudi leaders are also taking steps to prepare the human resources required in a scientifically-driven economy. Large numbers of Saudi students choose to study abroad, particularly in the United States. But the expensive, government-funded scholarship programme that enables this is vulnerable to the same falling oil revenues that gave it purpose in the first place. To survive, the scholarship programme must find ways to prove its value to the kingdom (page S64).

It will be these young people, with ideas and values that may challenge Saudi Arabia's entrenched conservatism, who must spearhead the country's science-powered economic transformation. At present, the country's young graduates are not fulfilling their potential - unemployment amongst this group is high, particularly for female graduates. The Nature Index sought out some of the women who have thrived in their science careers in the kingdom (page S70). Saudi Arabia is a country challenging itself to change from the top-down and the bottom-up all at once, and its neighbours and the wider international community will be following its future closely.

\section{Richard Hodson}

Supplements editor

\begin{abstract}
EDITORIAL: Richard Hodson, Stephen Pincock, Rebecca Dargie, Herb Brody, Victoria Kitchener, Sedeer El-Showk, Nadia El-Awady, Louise Sarant. ANALYSIS: Aaron Ballagh, Alexander Scherrmann. ART \& DESIGN: Mohamed Ashour, Madeline Hutchinson, Wojtek Urbanek. WEB \& DESIGN: Bob Edenbach, Olivie Lechevalier, Naomi Nakahara, Pamela Sia, Bart Riepe. DATA QUALITY: Jörn Ishikawa, Yuxin Wang, Jennie Pao, Pau Glaeser. PRODUCTION: Sue Gray, Kar Smart, lan Pope, Matt Carey, Ali Mosud, Nik Spencer. MARKETING: Stacy Best Ruel, Adil Jouhadi. PROJECT MANAGEMENT: Rebecca Jones. SALES: William Mahfoud, Jon Giuliani. ART DIRECTOR: Kelly Buckheit Krause. PUBLISHING Nick Campbell, Richard Hughes, David Swinbanks.
\end{abstract}

NATURE INDEX 2017 SAUDI ARABIA Nature Index 2017 Saudi Arabia, a supplement to Nature, is produced by Nature Research, the flagship science portfolio of Springer Nature. This publication is based on data from the Nature Index, a Nature Research web site maintained and made freely available at natureindex.com.

\section{NATURE EDITORIAL OFFICES}

The Campus, 4 Crinan Street,

London N1 9XW, UK

Tel: +44 (0)20 78334000

Fax: +44 (0)20 7843 4596/7

\section{CUSTOMER SERVICES}

To advertise with the

Nature Index, please visit natureindex.com/client-services feedback@nature.com

Copyright (@) 2017 Macmillan

Publishers Limited, part of Springer

Nature. All rights reserved. 